\title{
Walking Builds Community Cohesion Survey of Two New Hampshire Communities Looks at Social Capital and Walkability
}

\author{
Shannon H. Rogers, Kevin H. Gardner, and Cynthia H. Carlson
}

$\mathrm{W}$ alkability is an increasingly important feature of communities. Recent surveys by the Urban Land Institute find that even in the suburbs, residents want more walkable spaces, higher density development, and better transit. ${ }^{1}$ The millennial generation in their 20s and early 30 s is also seeking more walkable and higher density, nucleated development, in both cities and suburbs, and the aging Baby Boomers want communities that allow them to age in place. Communities with safe sidewalks, good lighting, and well designed, compact development with easy access to shops, parks, schools, and dining-walkable in other words-are linked to greater health benefits, higher home values, and better mental health, according to Urban Land Institute reports. This brief finds another benefit: more walkable communities are associated with higher social capital, a key ingredient in both vibrant, connected communities and the kinds of social networks that make life more enjoyable and healthier.

The central premise of social capital is that social networks have value. Social capital refers to the collective value of all "social networks" [who people know] and the inclinations that arise from these networks to do things for each other ["norms of reciprocity"].

\section{-Saguaro Seminar, Harvard University}

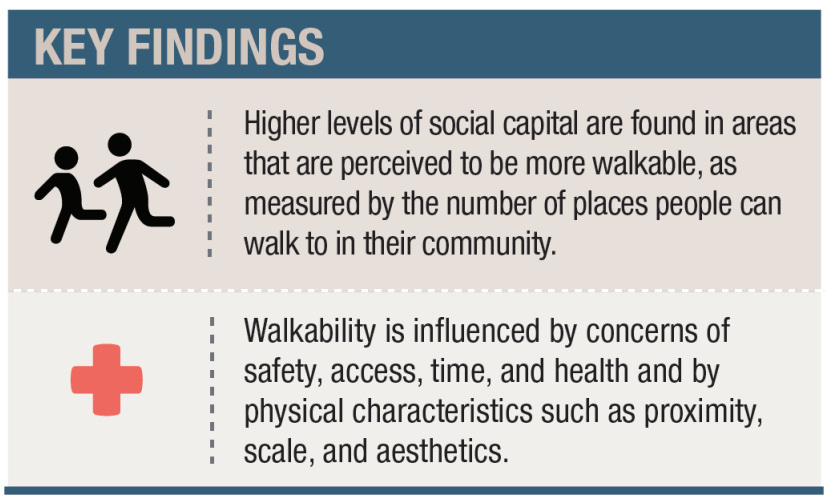

\section{Benefits of Social Capital}

There are numerous definitions and much theoretical and practical research on "social capital." We used the definition and measurement tools made popular by Harvard political scientist, Robert Putnam, and his Saguaro Seminar (an institution established in the late 1990s that continues to explore social capital and its implications in America). ${ }^{2}$ This group defines social capital as the value of social networks, and this value partly comes from trust in networks as well as the sense of reciprocity that develops (for example, if I do something for you, you are likely to feel inclined to do something for me). Because it can be challenging to assess a community's social networks on a large scale, Putnam measures the value of social capital through the proxy variables of community involvement and trust and, after conducting several national surveys, his group made a "social capital short form survey" available to the public. We utilized a number of these tried and tested questions in our research. 
Social capital and the networks that generate it have been shown to have many benefits and advantages, ${ }^{3}$ including the following:

- Material goods \& services: Individuals in a social network can often provide informal services such as health care, child care, and housing.

- Information: Networks allow individuals access to many sources of information whether it be about a job lead or other resources for daily life.

- Reduced transaction costs: Trust and reciprocity that make up social capital stocks can make it easier to interact within and among groups and thus make these interactions more efficient in terms of time and cost.

- Emotional support: Individuals with strong social networks see positive mental health benefits.

- Reinforcement of positive behaviors: Individuals looking for support or role models for promoting behavior changes, such as quitting smoking, may find that in positive social networks.

- Service brokerage: Direct connections between individuals can help in finding jobs or in finding services or assistance to meet other needs.

These benefits combine to promote a community that may have less crime and more stability without the need for expensive interventions from the public sector.

\section{Surveying Residents in Two New Hampshire Cities}

This brief is based on results from a survey of approximately 2,000 households in Portsmouth and Manchester, New Hampshire. We conducted the doorto-door survey in 20 neighborhoods in these two communities during the summer of 2009. Experts in each municipality helped us choose the specific neighborhoods based on levels of socio-economic diversity and varieties of built form (we were looking for a mix of built types from compact to suburban/sprawling). One hundred randomly selected individuals received our survey in each neighborhood. ${ }^{5}$ The response rate was 35 percent, or about 700 respondents.

We chose the cities of Manchester and Portsmouth as case study communities because of the variety of built forms and neighborhood types, interest, and commitments to sustainable community development and pre-existing collaborations.
Manchester is New Hampshire's largest city with more than 100,000 residents. It is also the most diverse population, mostly owing to its role as the state's Refuge Resettlement Area. In addition, Manchester offers a diversity of neighborhood types, from sprawling suburban to older, more compact neighborhoods close to the central city. It also has a strong commitment to economic development and social equity.

Portsmouth is a city of approximately 22,000 located in the Seacoast area of New Hampshire. A port city that has been a key part of the northern New England economy since colonial times, Portsmouth is also a progressive community. The city has a history of active and engaged individuals coming together to address pressing local and national issues. In November of 2007, Portsmouth became the first eco-municipality on the East Coast of the United States. ${ }^{6}$

\section{Walkability Is Tied to Higher Social Capital}

Survey results show that neighborhoods with higher perceived walkability had higher levels of social capital (see Table 1). Neighborhoods with higher incomes have both more walkable neighborhoods and higher social capital. However, demographics are fairly similar across the groups, so this does not account for the significant differences observed in social capital.

Many of the survey questions, such as those that asked respondents about their levels of trust for neighbors and other members of the community as well as frequency of participation in community events such as public meetings or committees were statistically analyzed and placed into two indices-community and trust. Figure 1 compares those indices between the more and less walkable neighborhoods: individuals who walked to more locations in their neighborhood or community had higher levels of community involvement and trust. This suggests a correlation between social capital and self-perceived walkability.

For respondents in this survey, well maintained sidewalks, lighting, and mixed-use development were particularly important to them. Survey respondents were asked what could be done in their neighborhood to make them more likely to walk. More and better-quality sidewalks was the most common response, followed by safety issues (including crime levels and lighting) and having actual locations 


\section{TABLE 1: COMPARING THE RESPONSES OF THOSE WHO PERCEIVED THEIR COMMUNITY TO BE MORE WALKABLE WITH THOSE WHO PERCEIVED THEIR COMMUNITY AS LESS WALKABLE}

\begin{tabular}{|c|c|c|}
\hline CHARACTERISTIC & MORE WALKABLE & LESS WALKABLE \\
\hline & DEMOGRAPHICS & \\
\hline AVERAGE AGE & 50 & 54 \\
\hline VERY OR MODERATELY CONSERVATIVE & $22 \%$ & $33 \%$ \\
\hline VERY OR MODERATELY LIBERAL & $47 \%$ & $32 \%$ \\
\hline VERY HAPPY & $33 \%$ & $25 \%$ \\
\hline EXCELLENT HEALTH & $27 \%$ & $21 \%$ \\
\hline AVERAGE INCOME RANGE & $\$ 62,500-\$ 87,500$ & $\$ 62,500-\$ 87,500$ \\
\hline AVERAGE EDUCATION LEVEL $\quad$ BA & ACHELOR'S DEGREE & BACHELOR'S DEGREE \\
\hline ATTEND RELIGIOUS SERVICES ALMOST EVERY & $24 \%$ & $27 \%$ \\
\hline \multicolumn{3}{|l|}{ WEEK OR MORE OFTEN } \\
\hline \multicolumn{3}{|c|}{ NEIGHBORHOOD PHYSIGAL PERCEPTIONS } \\
\hline AVERAGE NUMBER OF PLACES CAN WALK TO & 10 & 3 \\
\hline \multicolumn{3}{|l|}{ (OUT OF 13 OPTIONS) } \\
\hline HOW MANY MINUTES ARE YOU WLLING TO WALK & 21 & 19 \\
\hline \multicolumn{3}{|l|}{ TO A DESTINATION? } \\
\hline \multicolumn{3}{|c|}{$\begin{array}{r}\text { TRAVEL BEHAVIOR } \\
\end{array}$} \\
\hline WALK EVERY DAY OR SEVERAL TIMES PER WEEK & $55 \%$ & $23 \%$ \\
\hline BIKE EVERY DAY OR SEVERAL TIMES PER WEEK & $11 \%$ & $5 \%$ \\
\hline RESIDENTS WHO COMMUTE TO WORK & $71 \%$ & $67 \%$ \\
\hline OF THOSE WHO COMMUTE, \% GOING BY CAR & $89 \%$ & $95 \%$ \\
\hline \multicolumn{3}{|c|}{$\begin{array}{l}\text { SOCIAL CAPITAL METRICS } \\
\end{array}$} \\
\hline PEOPLE CAN BE TRUSTED* & $41 \%$ & $27 \%$ \\
\hline REPORTED TRUSTING NEIGHBORS A LOT* & $52 \%$ & $41 \%$ \\
\hline PARTICIPATE IN A COMMUNITY PROJECT IN LAST & $55 \%$ & $43 \%$ \\
\hline \multicolumn{3}{|l|}{ LAST YEAR* } \\
\hline HAVE FRIENDS AT YOUR HOME IN LAST YEAR* & $95 \%$ & $91 \%$ \\
\hline VOLUNTEERED IN LAST YEAR* & $75 \%$ & $67 \%$ \\
\hline ATTENDED CLUB MEETING IN LAST YEAR* & $67 \%$ & $58 \%$ \\
\hline AGREE THAT TV IS MY MAIN FORM OF & $37 \%$ & $47 \%$ \\
\hline ENTERTAINMENT & & \\
\hline
\end{tabular}

Note: An asterisk (*) indicates a statistically significant change $(p<0.05)$.

(such as "third places") to visit. "Third places" refer to locations in addition to home and work where people gather in a community: a coffee shop, library, or park, for example.

Given the connection between higher social capital and other positive outcomes for individuals, these results suggest that walkability is an important element in the built environment above and beyond the documented effects on health and the environment.

\section{Policy Implications}

Given this link between walkability and greater social capital, and in turn the link between social capital and numerous positive outcomes, refitting communities with greater walkability can have short- and longer-term payoffs. Individuals with stronger levels of social capital have been shown to live longer and happier lives with reduced transaction costs for many daily activities. A more walkable community can reduce time traveled in the car and thus leave more time for other activities within the family
FIGURE 1: RESIDENTS WHO PERCEIVE THEIR COMMUNITY TO BE WALKABLE HAVE HIGHER LEVELS OF TRUST AND COMMUNITY INVOLVEMENT

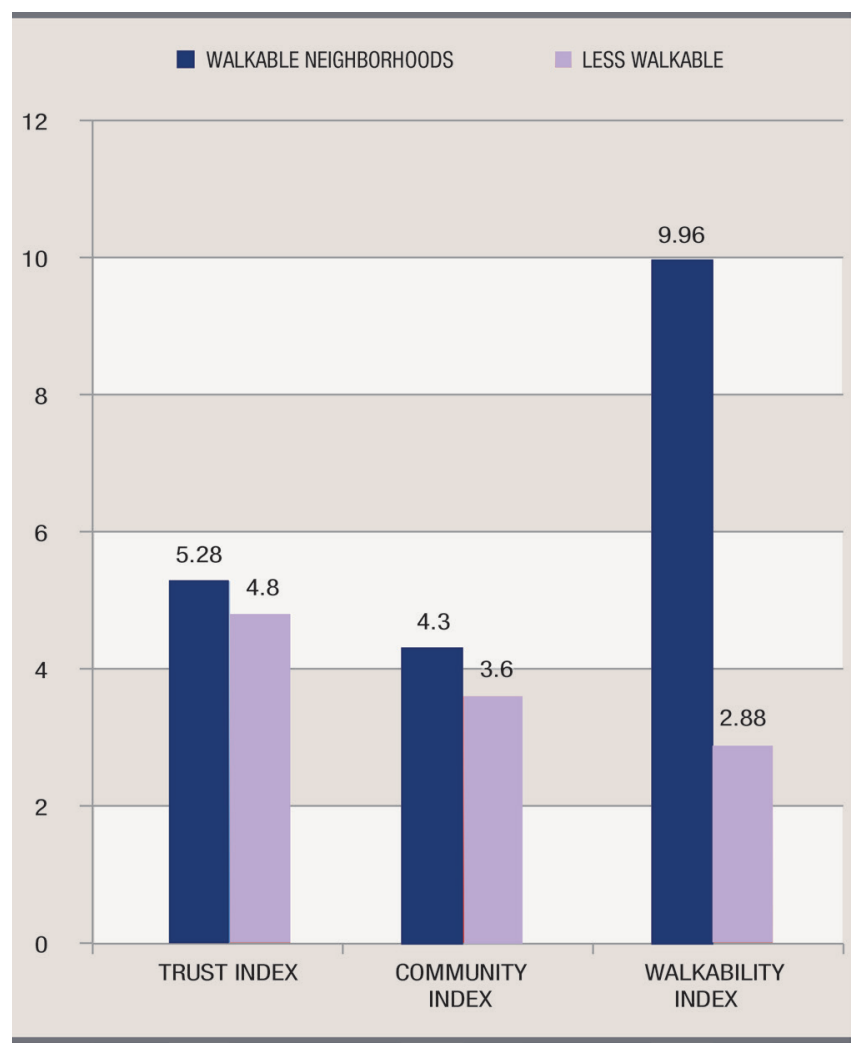

or community. In fact, Putnam has shown that a 10 minute increase in commuting time leads to a 10 percent reduction in all forms of social capital. ${ }^{7}$

Developers and urban planners have already noted the rising value of homes in neighborhoods that are more walkable. One study found that homes in walkable neighborhoods were worth on average $\$ 34,000$ more than similar homes in neighborhoods with average walkability. ${ }^{8}$

While the marketplace will likely respond to this growing demand for walkable, denser, and more accessible living without policy intervention, policy still plays a role in the built environment.

\section{Creating Incentives}

Policy can be designed to create incentives that promote more walkable, denser, and more equitable communities. Local zoning is an example (density requirements, for example). 
- Massachusetts created incentives in its Compact Neighborhoods program for diverse, walkable neighborhoods by ensuring that if municipalities met a set of criteria for walkability and density, they would receive preferential treatment in applications for state assistance funds. ${ }^{9}$

- Local governments can also create incentives to locate schools nearer new residential developments to ensure walkability for students and parents. Local governments in Illinois have used land cash ordinances that require developers to dedicate land (or contribute cash) to provide public services for residents of the new development. ${ }^{10}$

\section{Promoting Equitable Development}

Issues of equity are also critical to address. Too often, the most walkable and livable communities are higherincome communities. Ensuring that low-income communities are walkable is critical to develop social capital and allow individuals to realize its benefits.

- The Obama Administration's Interagency Partnership for Sustainable Communities, which includes the Department of Housing and Urban Development (HUD), the Department of Transportation (DOT), and the Environmental Protection Agency (EPA), was created to promote the idea that transportation, energy efficiency, and housing should be addressed together instead of in a mutually exclusive nature. ${ }^{11}$

- The Partnership also has developed several data tools that allow communities to map their own walkability and other livability scores. The tools allow policy makers and residents to feed the data to local planners, municipal departments, and others who are responsible for ensuring neighborhoods are walkable, safe, and livable.

\section{Funding and Training}

Funding options and technical assistance are available to communities through a variety of federal and state sources.

- HUD's Sustainable Communities Initiative provides competitive grants, for example. Community Development Block Grants are another source of funding, as is the Choice Neighborhoods grant program.
- Technical assistance is also available through the federal government to communities. For example, the Smart Growth Implementation Assistance helps communities integrate smart growth strategies into their planning.

More than half of Americans want to live in a community that creates easy access to shops, restaurants, and work places. ${ }^{12}$ Eight in ten older Americans want to age in their current homes, which means becoming less dependent on their cars. More walkable communities are healthier communities, and as this research shows, residents in them are more connected to one another not only by sidewalks but also through the social networks and social capital they form when they live in communities that encourage gathering and meeting face-to-face.

\section{Survey Design and Data Collection}

We employed a community-based approach that drew on many of the principles of Community Based Participatory Research. ${ }^{13}$ The research process involved interviews and focus groups with key informants, municipal decision makers, and neighborhood leaders that focused on trying to understand how these groups think about and measure social, environmental, and economic factors in their planning and development. This local knowledge assisted us in determining how neighborhoods varied in built form (that is, urban mixed use neighborhoods; suburban/less dense neighborhoods) and in socio-demographic characteristics, and subsequently which areas to investigate.

Similar to research conducted in Ireland, we collected information on walkability through answers to a series of questions about which locations individuals perceived they could walk to from their home. ${ }^{14}$ These locations included a post office, restaurant, home of a friend, grocery store, coffee shop/café, bar/pub, shopping center, community/recreation center, church, convenience store, school, natural area/open space/ park, and library/bookstore. We used these responses to create a self-reported walkability score for each respondent and then to determine if an individual lived within a more or less walkable neighborhood. The median number of locations was seven. "Less walkable" were therefore locations in which residents named fewer than seven places they could walk to. 
To measure social capital, we asked survey respondents to indicate their levels of trust for various groups and individuals. Being able to trust one's neighbors or people in the community is a key factor in strong social capital because trust is the glue that binds residents and communities together. Without it, cooperation is nearly impossible. We also asked residents about their frequency of participating in community activities including volunteering, attending public meetings, visiting friends, and attending organizational meetings (among others). We compiled their responses into three indices using factor analysis: trust, community, and walkability.

A response rate of approximately 35 percent (which is in line with other surveys of this size and budget) yielded nearly 700 returned surveys.

As with all survey research, selection bias is a possibility. Individuals who enjoy walking may choose to live in more walkable neighborhoods. Our sample was wealthier, more educated, more female, and older than the general population, which is often typical of survey respondents. Other factors such as family size and weather may also play a role in perceptions of walkability. Despite these caveats, the correlation between walkability and social capital provides further evidence for the consideration of social capital as a key component of quality of life.

\section{End notes}

1. Urban Land Institute, “'Ten Principles for Building Healthy Places' and 'Intersections: Health and the Built Environment' Explore Role of Land Use in Creating Healthy Communities" (Washington, DC: ULI, 2010). Available at www.uli.org/press-release/10-principles-for-buildinghealthy-places-and-intersections/; see also, Urban Land Institute, "America in 2013: A ULI Survey of Views on Housing, Transportation and Community (Washington, DC: ULI, 2013), available at www.uli.org/research/centers-initiatives/ terwilliger-center-for-housing/research/community-survey/.

2. See www.hks.harvard.edu/programs/saguaro/.

3. M. Duncan, "Social Capital in America's Poor Rural Communities., S. Saegert et al. (eds.) Social Capital and Poor Communities (New York: Russell Sage Foundation, 2001).

4. Policy Research Institute, "Social Capital as a Public Policy Tool," Canada. ISBN 0-662-41093-9. Located at www.horizons.gc.ca/sites/default/files/Publication-alt-format/20030183-eng.pdf. Accessed on March 6, 2014.
5. Because the selection process was random at one level and more targeted at the first, we employed multilevel modeling techniques in our analysis.

6. Personal communication from Peter Britz, Environmental Planner and Sustainability Coordinator, Portsmouth, NH, 2008.

7. See www.hks.harvard.edu/saguaro/factoids.htm.

8. Urban Land Institute, "Ten Principles."

9. See www.mass.gov/hed/community/planning/compactneighborhoods.html.

10. See http://activetransportationpolicy.org/node/107.

11. See www.sustainablecommunities.gov.

12. Urban Land Institute, "Ten Principles."

13. L. R. O'Fallon and A. Dearry, "Community-based participatory research as a tool to advance environmental health sciences," Environmental Health Perspectives, 110(Suppl 2) (2002): 155-159.

14. K. Leyden, "Social Capital and the Built Environment: The Importance of Walkable Neighborhoods," American Journal of Public Health, 93(9) (2003): 1546-1551.

15. For more details on the study, please see the following peer reviewed, journal publications:

S. H. Rogers et al., "Walkability and Social Capital as Indicators of Quality of Life at the Municipal and Neighborhood Scales," Journal of Applied Research in Quality of Life (2010). DOI: 10.1007/s11482-010-9132-4.

S. H. Rogers et al., "Measuring community sustainability: exploring the intersection of the built environment \& social capital with a participatory case study," Journal of Environmental Studies \& Sciences (2012). DOI: 10.1007/s13412-0120068-x.

C. H. Carlson et al., "Complexity in Built Environment, Health, and Destination Walking: A Neighborhood-Scale Analysis," Journal of Urban Health (2012). Published online first. DOI: 10.1007/s11524-011-9652-8.

S. H. Rogers, K. H. Gardner, C. H. Carlson, "Social Capital and Walkability as Social Aspects of Sustainability," Sustainability, 5(8) (2013): 3473-3483 (part of Special Issue: Measuring Socio-Economic Well-Being). This article is available for free from an open access journal. 


\section{About the Authors}

Shannon Rogers is an assistant professor of environmental science and policy at Plymouth State University and an ecological economist in the University's Center for the Environment. Rogers is also a senior fellow in the Environmental Leadership Program (shrogers@ plymouth.edu).

Kevin Gardner is a professor of civil engineering at the University of New Hampshire, a senior fellow at the Carsey Institute, a member of the Environmental Research Group, and associate director of the NH EPSCoR program (kevin.gardner@unh.edu).

Cynthia Carlson is an assistant professor of environmental science at New England College and a senior fellow in the Environmental Leadership Program (ccarlson@ nec.edu).

\section{A c k n o w l edgements}

The research described in this paper has been funded in part by the United States Environmental Protection Agency (EPA) under the Science to Achieve Results (STAR) Graduate Fellowship Program. EPA has not officially endorsed this publication and the views expressed herein may not reflect the views of the EPA. Support was also provided by the Environmental Research Group at the University of New Hampshire and the Natural Resources \& Earth Systems Science Program. The authors would like to thank Sarah Kissell, Joanne Theriault, and Ben Brown for their assistance with data collection. We appreciate the participation of Manchester and Portsmouth City official and community members, as well as the assistance of Kevin Leyden in the early stages of this research. And thanks to Michele Dillon, Curt Grimm, Laurel Lloyd, Bruce Mallory, Beth Mattingly, and Amy Sterndale at the Carsey Institute for their helpful comments and suggestions.

\section{Nu University of New Hampshire

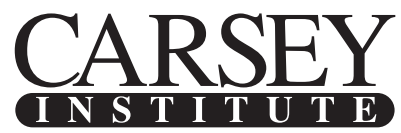

Building knowledge for families and communities

The Carsey Institute conducts policy research on vulnerable children, youth, and families and on sustainable community development. We give policy makers and practitioners timely, independent resources to effect change in their communities.

This work was supported by the United States Environmental Protection Agency under the Science to Achieve Results (STAR) Graduate Fellowship Program, the Environmental Research Group at the University of New Hampshire, and the Natural Resources \& Earth Systems Science Program.

Huddleston Hall

73 Main Street

Durham, NH 03824

(603) 862-2821

TTY UsERS: DIAL 7-1-1 OR 1-800-735-2964 (RELAY N.H.)

www.carseyinstitute.unh.edu 